\title{
Research on Yao Si's "Expectation Horizon"
}

\author{
Nana Chen \\ Zhengzhou University of Industrial Technology, Zhengzhou, Henan, 451100
}

Keywords: Expectation Vision, Theoretical Origin, Psychological Mechanism, Function

\begin{abstract}
This paper looks forward to this important concept from three aspects: the theoretical origin of expectation, the psychological mechanism of expectation and the role of expectation in the field of view, which is called "the pillar of methodology" by Yao Si as the most important article in the study of esthetics. The first.
\end{abstract}

\section{Introduction}

In the 1960s, the acceptance of aesthetics by German scholar Yao Si had a wide influence in the world. It reversed the criticism of British and American New Criticism and Structuralism ontology, and transferred the focus of criticism directly to the recipients of literary works - - the reader, the reader's position to an unprecedented height. Aesthetics in the emphasis on the reader as the center at the same time, explained the "why should the reader as the center and how to achieve and highlight the reader's central position", and ultimately deduce the history of literature should not only writer history, works history, history.

Yao's study of literary acceptance is from the analysis of "look forward to vision", it is "Yao Si basic theory of the most important concept." Expectation of vision "refers to the literature to accept the activities of the reader's original experience, Taste, literacy and other comprehensive form of the literary works of appreciation and appreciation of the level, in the specific reading, the performance of a potential aesthetic expectations.

\section{The "expectation of vision" theory}

"Looking forward to the vision" is not the first pioneer of Yao Si, the founder of phenomenology Husserl and existentialist pioneer Heidegger have used the "vision" or "vision" of the concept, and the interpretation of the representative of Gadamer Is used as a key concept and frequently used. "Vision" refers to the experience and knowledge received from tradition and prejudice. "Vision" is constantly formed, continuous development, expanding. Gadamer believes that "vision" is the people from the existing experience and knowledge can reach the scope of understanding.

The first to "look forward to" and "vision" together is the use of scientific philosopher Popper and sociologist Mannheim. Gadamer argues that the interpreter carries the "foresight" in the act of interpreting, that is, Heidegger's "first knowledge" constitutes Gadamer's so-called "understanding of vision". "Preconceived" is "preconceived", that is, the interpreter in the interpretation of the behavior before the beginning of all the relevant understanding, Gadamer also called "before projection". Heidegger and Gadamer called "understanding of vision" was Yao Si transformed into "look forward to vision." Gadamer inherited the view of Heidegger's "pre-understanding" and put forward the concept of "legal prejudice" and "vision fusion". [1] He argues that the prejudice in understanding is "legitimate prejudice" because everyone lives in a particular era, in a particular historical and cultural atmosphere, and thus inevitably carries his own times and personal prejudices; And the works of art and recipients have their own "vision", because the former is a specific historical conditions created by a specific person, which is living in a particular historical situation in the people, only to achieve "vision fusion" to understand the text The 


\section{Look forward to the psychological mechanism of vision}

If Hermeneutics is the theoretical basis for the development of aesthetics, then Piaget's epistemology is an important factor in accepting the spread of aesthetics. The epistemological doctrine of constructivism provides an epistemological mechanism of psychology in accepting aesthetics. Piaget uses the four basic categories of schema, assimilation, adaptation and balance to describe the psychological processes of cognition and construction. The schema refers to the structure of cognition, the structure of psychological function, etc., which is subjective in recognizing objective things. It is a structure of activity because, in addition to the original genetic schema that is the physiological basis of the schema, are acquired in the interaction with the object gradually built. In Piaget's view, the construction of the main schema is actually the process of mutual adaptation of the subject and object, in this process includes two important psychological mechanisms, namely, assimilation and adaptation. Assimilation is the subject of the object into the main body of the schema, the subject is a subtle change in the gradual process, is the root cause of the reaction, but also the origin of beauty; adaptation is the main adjustment of the original schema or the creation of new Schema, which causes a change in pattern quality. Assimilation is a stable factor in the understanding of the structure, is the most basic psychological function; compliance reflects the subject to adapt to changes in the external environment of the subjective initiative. The establishment of the main body of cognition is the result of the coordination and balanced development of the two.

Yao Si was blessed to worship the "Lady Bovary" and Fetto "Fernie" two works as an example. In the early stages of the release, the latter is popular, while the former is nobody cares, Yao Si will be attributed to the reader's vision of hope can not accept Flaubert in the form of "non-personal narrative" [2] principle of innovation, With the success of the former world, the reader finally recognized the new expectations of the standard, which makes the fancy style of the latter to become a flash in the pan. From this example shows that the reader's vision of expectation is to change and adjust the process of assimilation and adaptation of the subject's own psychological schema. It is similar to the general mechanism of recognizing the psychological schema, and is similar to the opposite in the role of assimilation and adaptation. Therefore, the use of Piaget's epistemology to explain the acceptance of the subject look forward to the formation, adjustment and construction is a theoretical basis.

\section{Look forward to the role of vision}

Any literary works that are in an independent state are associated and united by means of the expectations of the author and the reader. Between the reader and the work, the reader and the author between the relevant and unified intermediary is looking forward to vision. As the object of the aesthetic object before reading, is a push of cold words, only after the reader's reading, its social significance and aesthetic value can be expressed in order to translate the meaning of the text into reality. Any reader to read a literary works, his cultivation, experience, literary ability, such as a comprehensive weaving into a network of aesthetic expectations, through it to interpret the works, appreciate the works. Yao Si believes that the vision is the reader of the literature to accept the starting point and foundation. It mainly includes three aspects: First, the literary works of a certain type and standards of familiarity and mastery. This empirical grasp becomes an intrinsic measure that works as a "pre-understanding" of the reader's reading. Second, familiarity with some of the works in the history of literature, including their contents and forms, themes and styles, and so on, are also accumulated in the reader's mind as a reading experience, forming the psychological and new works A secret relationship, he will unconsciously with the formation of past works to read the look of new works. Third, the reader is in practice and reality activities and life, so he can not abandon the reading of the reality and practice of psychological experience, this experience as a reference system into the reader's reading horizon. Readers sometimes compare the fictional world in the work with the real world of reality, comparing the literary language to the everyday language. 
The vision plays a great role in reading and receiving, but it does not passively accept the work, but rather chooses and recreates the original work. In the acceptance of the main body is always based on their own vision, the aesthetic object to be selected. [3] Of course this choice will not be static, it will change with the expected vision changes. The main body in the acceptance process, choose with its cultivation, quality, interest and other aesthetic objects consistent. And when it receives a lot of aesthetic information in the face of the object world, the subject is always the most sensitive to capture and perceive those with their experience, personality, expectations and other objects. For example, for the "Dream of Red Mansions", because of the reader's cultivation, temperament, interest and other differences and have different understanding, there are love theme that there are political struggle theme, anti-feudalism, etc., can be described as a thousand readers Thousands of Hamlet. While looking forward to the vision to help the reader to make a unique discovery of the work, so that he found from the work and insight into others no, and even the author may not be aware of the new meaning and new reality, so as to give the work more and more Meaning and aesthetic value. The reader's vision of the judge determines the degree of acceptance of the reader, so the work to be accepted, we must consider the reader's expectations factors. Moreover, any writer in the literary creation, always want their works can be better accepted by the reader, because the creation in a sense that is the realization of the writer's own, only when the writer's work is recognized and accepted by the reader in order to further prove and realize the writer's self. This writer in the creation of intentionally or unintentionally concerned about and study the reader's vision, and strive to find the connection between the self and the reader in order to obtain the reader's recognition and appreciation. Therefore, in the literary creation, the writer will certainly take into account the reader's vision of hope.

First of all, writers in the creation, tend to predict the reader's vision to see whether their works in line with the reader's aesthetic taste, whether the reader can understand and accept. Such as the poet of the Tang Dynasty poet Bai Juyi always in accordance with the aesthetic taste of civilians readers, thoughts and feelings and accept the level of creation, profound thoughts always in plain language, so that his works can spread thousands of households, Heart and soul. Again, after the publication of a work, the reader's vision of the judge determines the degree of acceptance of the work of the reader, and from the reader's acceptance of the author can see the author's creative ideas and the process of the forecast and the reader's vision is consistent, prompting writers to analyze the reasons for them in order to adjust their creative ideas when creating. At the same time, there is a aesthetic distance between the prospective vision and the new works. Every time the acceptance of the innovative works will negate the previous experience, generate new acceptance consciousness from the new experience, and the new works will pass the new expectation New problems and new questions require writers to make new adjustments. So the production of literature in the expected vision is relatively stable and constantly changing factors, the continuous development of the.

Yao's acceptance of aesthetics puts the reader in a prominent position and becomes a starting point for literary studies. In the process of accepting, the reader chooses the work with his own "vision of hope". With the improvement of the level, the reader's original "vision of hope" is broken or expanded to form a new "vision of hope". Or the expansion of the "look forward to vision" and put forward new demands on literature. Feedback to the author's creative activities, the writer will try to pull away with the reader's vision of the distance, and constantly create a new work with the reader's "look forward to vision" integration, which constitutes a cycle of rising process. Therefore, although Yao's theory still has many imperfections, such as in the emphasis on the reader's central position is inevitably some overkill, but through the "look forward to the vision" to achieve the author, works and readers between the three dynamic Relations, so that art production and acceptance of interaction, so now dialogue with the past, in today is of great significance.

Expectation of vision as an important concept of acceptance of aesthetics, it is in the continuous acceptance of the work of the accumulation and formation, it quietly restricts the production of literature and works of acceptance, for its research will have a deeper and broader of the field. 


\section{References}

[1] Dong Xuewen. Western literary theory [M]. Peking University Press, 2005

[2] Jin Yuanpu. Literary Hermeneutics [M]. Northeast Normal University Press, 1998

[3] Zhu Liyuan. Contemporary Western literary theory [M]. East China Normal University Press, 2005

[4] Xie Linxia. On Yao Si's theory of "expectation" [J]. Journal of Inner Mongolia Agricultural University, 2008,4 (10)

[5] Cao Wengang. Journal of Huaihai Institute of Technology, 2012,10 (1)

[6] Chen Lingling."Journal of Chifeng University, 2010,31 (2) 